\title{
School Career of One-sided Talented Students in Secondary Education in the Netherlands
}

\author{
Pieter A.C. Wisse ${ }^{1}$, Mirjam Roelse ${ }^{2} \&$ Wilfried F. Admiraal ${ }^{3, *}$ \\ ${ }^{1}$ Christelijke Scholengemeenschap Walcheren, Middelburg, the Netherlands \\ ${ }^{2}$ Middelburg Administration, Middelburg, the Netherlands \\ ${ }^{3}$ Leiden University, Leiden, the Netherlands \\ *Corresponding author: Leiden University Graduate School of Teaching, Leiden University, Wassenaarseweg 62A, \\ 2333 AL, Leiden, the Netherlands. Tel: 31-71-527-6081. E-mail: w.f.admiraal@iclon.leidenuniv.nl
}

Received: May 21, 2014

doi:10.5430/wje.v4n4p43
Accepted: July 21, $2014 \quad$ Online Published: July 31, 2014

URL: http://dx.doi.org/10.5430/wje.v4n4p43

\begin{abstract}
Dutch mainstream education is a selective school system. Students are selected for different ability tracks at the age of 12. They are grouped to perform at the same level in all subjects, even though the students differ significantly in proficiency in mathematics and languages. Analysis of the streaming of 598 students in the first years of secondary education shows that, compared to other students, significantly more one-side-talented students with proficiency in either mathematics or languages attended the lowest ability level. In life-world interviews, ten former students with high proficiency in either mathematics or language, reflected on their school careers and crucial time moments during their school career. They report that they did not experience these moments as disappointing. Even so, following the lower ability track was not a solution to their problems as their stronger domains were not sufficiently challenged. Future research should focus on how students' different proficiencies can be addressed and further developed within the ability tracking system of Dutch secondary education.
\end{abstract}

Keywords: school career; educational tracking; mathematical proficiency; language proficiency

\section{Introduction}

In the Dutch selective school system students are tracked into differing-ability schools at the age of 12 . School placement policies as well as the quality of the various tracks are major issues in political debates (Onderwijsraad, 2010). The debate ensues on the relatively early age at which students are selected for different tracks, and with regard to the consequences this selection has for the educational development of students with talents in different domains. Within the tracks students have to perform at the same level in all school subjects, though they may differ significantly in their ability in some domains. The most profound differences are in proficiency in mathematics and languages, needed for the compulsory school subjects of Mathematics, Dutch and English as foreign language, as well as for the other subjects of the Dutch curriculum (e.g., foreign languages French, German and Spanish, Physics, Chemistry, Biology, History and Geography). There is a paucity of research on the consequences of this selection process for individual students with high proficiency in either mathematics or languages and for their development during their school career. In this study, former students, with a high proficiency in either mathematics or languages, reflect on this selection process and on their school careers.

\subsection{Ability Tracking}

In various educational systems, tracking is used to group students at different ability levels. Tracking is a form of whole-group instruction that is characterized by a single and set curriculum delivered at the same pace for all students in the class. Placement is based solely upon the child's ability level. The central argument in favor of tracking, either placement in different types of schools or placement in different tracks within the same school, is that homogeneous classrooms permit a focused curriculum and appropriately paced instruction that leads to maximum learning by all students (Kulik \& Kulik, 1982). Duflo, Dupas and Kremer (2011) studied 121 primary schools in Kenya and found beneficial effects for high-achievers and indirect effects for low-achievers. This indirect effect 
meant that teachers taught low-achievers to their level, which led to an increase in achievements. With ability tracking, the teacher does not have to worry about boring the fastest learners or losing the slowest ones. Students learn more in an environment where students have similar learning capacities (Dobbelsteen, Levin, \& Oosterbeek, 2002).

The counter argument in favor of heterogeneous classrooms is that the lower-track students are systematically disadvantaged by a slower learning environment that leaves them behind those in the upper tracks (Kalogrides \& Loeb, 2013; Sund, 2013). An analysis of international test scores such as TIMMS, PISA and PIRLS indicates that early tracking increases inequality in achievement (Brunello \& Checchi, 2007; Cobb-Clark, Sinning, \& Stillman, 2012; Hanushek \& Wößmann, 2006). This finding is confirmed in national data sets (e.g., Becker, Lüdtke, Trautwein, Köller, \& Baumert, 2012). Research in American schools suggests that the use of ability tracking not only leads to inequality in outcomes, but also disproportionally impacts minority students, economically disadvantaged students, and students with lower ability (cf., Argys, Rees, \& Brewer, 1996; Betts \& Shkolnik, 2000; Figlio \& Page, 2002). Kalogrides and Loeb (2013) studied student sorting within three large urban schools and found that classrooms with the most low-achieving, minority, and poor students were more likely to have novice teachers. The authors conclude that sorting students by achievement level exposes minority and poor students to lower quality teachers and less resourced classmates. Teachers' decisions in the tracking process have the potential to have a great impact on the careers and future lives of the students (Adelman 1999; Choy, Horn, Nunez, \& Chen, 2000; Darling-Hammond, 2000; Kelly, 2008; King, 1996; Lucas, 2001). Although there is a lack of evidence supporting the use of tracking at the secondary level, tracking is used in many educational systems (Oakes, 1992).

Tracking students of the same age in secondary education differs in the various education systems around the world (Van der Werfhorst \& Mijs, 2007). The Scandinavian and American school systems have a small number of tracks. Students with different ability levels go to the same school for secondary education, but tracking is commonly used within the school to group students in classes with others of the same academic capability (Bernhardt, 2012). In the USA, there is no strict separation between the tracks, and students can follow various school subjects at different levels (Van der Werfhorst \& Mijs, 2007).

\subsection{Dutch Education System}

The selective Dutch school system uses ability tracking of students beginning at age 12. Dutch mainstream education is summarized in Figure 1. Secondary education starts after completion of primary education, usually at age 12, and generally continues to the age of 16-18. Full-time education is compulsory up to and including the child's sixteenth year. In the final year of primary school a secondary school must be selected. This is done based on information gathered by the head teacher in the primary school and from a nationally organized test. With this information, a secondary school level is determined, and parents and children make a choice of a secondary school. There are more than 700 secondary schools in the Netherlands, both publicly and privately run. Dutch education is structured in a way that the final degree can be reached by several different study routes. This means that students have the possibility to switch from one level to another. It is possible to complete pre-university education after completing vocational training, but this detour requires two extra years and a lot of perseverance from the student.

After primary education, a student follows one of three possible school levels based on test scores and teacher recommendations:

1) pre-vocational secondary education (4 years; lower level) prepares the student for a practical internship followed by work, or followed by further vocational education.

2) senior general secondary education (intermediate level) takes 5 years and prepares the student for universities of applied sciences.

3) pre-university education takes 6 years (highest level) and is the admissions level for research universities.

Progression through secondary education depends on students' achievements, and a student may be required to repeat a school year or to transfer to a less demanding school level. Secondary students who fail a year twice are obliged to transfer to a less demanding school level.

\subsection{One-Sided Talented Students}

One of the more persistent problems in Dutch education relates to the inflexibility which is inherent to the system of educational tracking. For all school subjects, students are grouped to be instructed at the same level, although they may significantly differ in ability in some domains. 


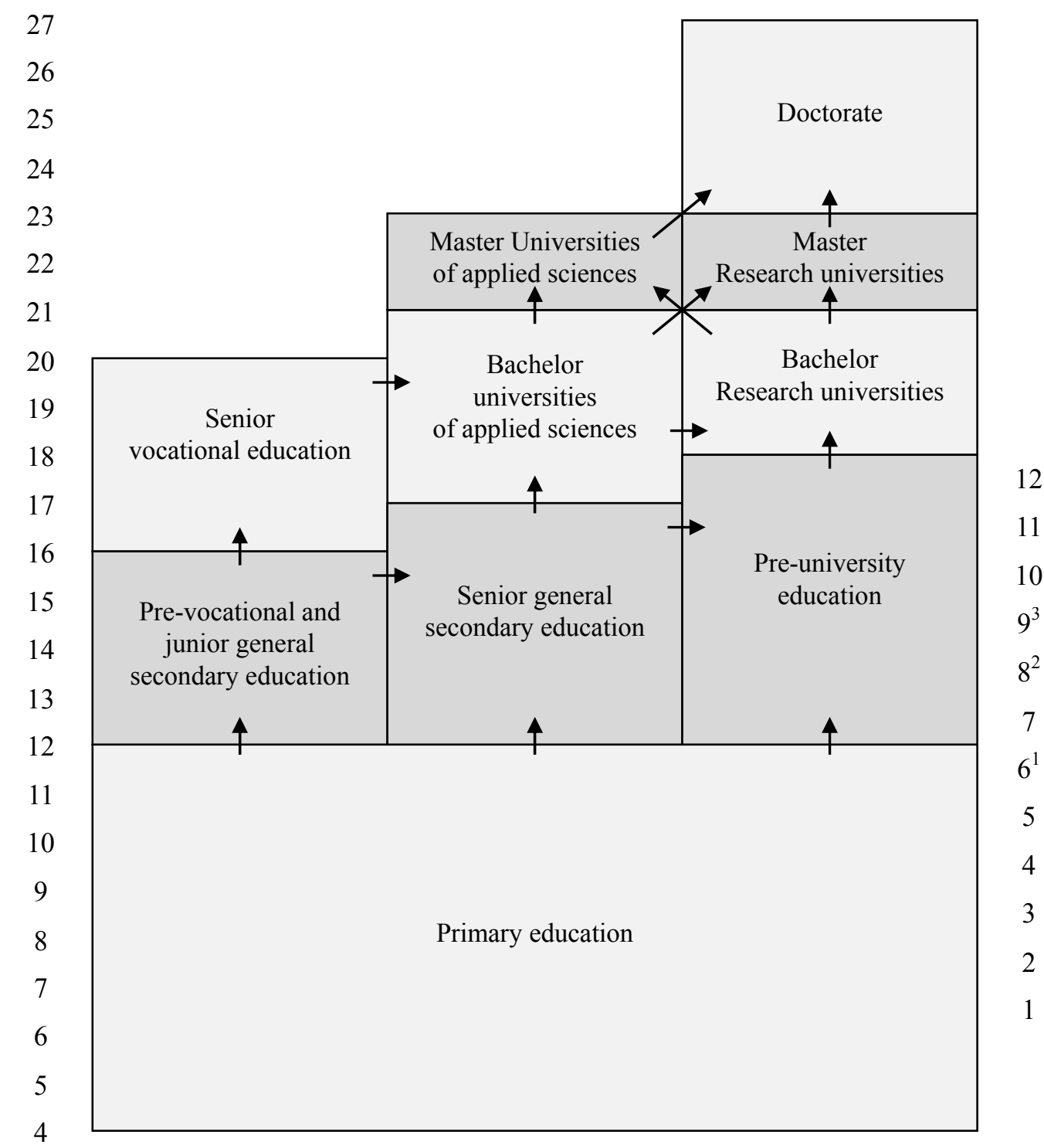

Age

Grade

${ }^{1}$ National test at the end of primary education

${ }^{2}$ Selection for educational track at the end of Grade 8

${ }^{3}$ Choice for educational profile at the end of Grade 9

Figure 1. Main Stream Education in the Netherlands

The focus of this study is on students with high proficiency in either mathematics or languages. These students achieved higher than average in languages (writing, reading and language learning), but received low scores in mathematics (arithmetic and algebra) or the other way around. Earlier studies found low correlations between proficiencies in mathematics and language (e.g., Österholm, 2006; Zepp, 1981), although learning mathematics also requires a particular level of language skills (cf., Ríordáin \& O'Donoghue, 2009). This seems to be especially the case in realistic mathematics education which is applied in many secondary schools in the Netherlands (Gravemeijer \& Doorman, 1999). Although in many Dutch secondary schools educational tracking is being postponed from age 12 to age 13 or 14, educational tracking based on the lowest ability level is still practiced in most secondary schools in the Netherlands. This means that one-sided proficiency students are forced to attend all their classes at the level corresponding to their lowest ability domain despite the fact that they have more talent in other school subjects. In this study, we are focused on the consequences of Dutch educational tracking for the school career of one-sided 
proficiency students. Two research questions were formulated:

1) How did one-side-talented students (in either numeracy or literacy) experience their school careers including the times when they were selected for the next phase?

2) Is there a difference in experiences of students with a high mathematical proficiency and students with a high language proficiency?

\section{Method}

\subsection{Participants}

Data have been collected from 11 student cohorts starting out in one secondary school in the south-west of the Netherlands between 1998 and 2008. This school is a regular secondary school with two highest ability levels: senior general secondary education and pre-university education and without any major curriculum changes during this period. From 1998 to 2008, 598 students took the national standardized test in Grade 6, the test that is used in many primary schools to help select the student's educational track in secondary school. This national test determines, among other things, students' proficiency in Dutch language and Mathematics. Furthermore, data were collected about the credits of the 598 students at the end of Grade 8 --- the moment when students were definitively selected for one of the three main educational tracks: pre-vocational education (which in this case meant that the student went to another school), senior general secondary education and pre-university education. After Grade 8, of the 598 students in the sample, 328 followed pre-university education in Grade 9 and higher and 270 students followed senior general secondary education.

School procedures with respect to school entrance and progress through the grades were checked with 10 other randonmly choosen secondary schools throughout the Netherlands. In general, the procedures were similar in all schools. With the exception of one school, the selection of students for one of the three tracks was based on the mean score for all subjects (Dutch, English, French, German, History, Geography, Biology, Mathematics and Physics). If students wanted to attend pre-university education in the next year, the mean score required varied from 60 to $75 \%$ (it was $70 \%$ for the school that participated in the current study). Five of the ten schools selected students for the different educational tracks in Grade 8; three schools selected at Grade 7, one in Grade 6, and one in Grade 9. In all schools, the consequence of not having met the criteria necessary to attend pre-university education in the next year was to repeat the particular year or to continue at a lower ability track.

From the group of 270 students of this particular secondary school, 10 students were randomly selected along the following criteria:

- they had already completed secondary school;

- in the national test at the end of primary education, they scored above the mean on Dutch language and average or below the mean on Mathematics or the other way around;

- they started secondary school in combination classes of pre-university/senior general education;

- at the end of Grade 8, they received a mean score of 70\% or higher in the language subjects (Dutch, English, French and German) and a score of $60 \%$ or lower in Mathematics and Physics, or the other way around;

- the difference between the mean scores in language subjects and Mathematics and Physics was at least 20\%, and

- they did not pass Grade 8 at a pre-university education level and had to move to the lower track of senior general secondary education.

\subsection{Measures}

Data on student performance in Mathematics and Dutch language were compiled from the national test at the end of primary school. Data about what educational track students followed were collected in Grade 8 (just before the selection of educational track) and Grade 9 (just after the selection). These data were taken from records of the school administration.

Data about the school careers of the ten students who were selected, were gathered in semi-structured life-world interviews that seek to obtain descriptions of the students' lived world with respect to interpretation of the meaning of crucial moments of their school career (cf. Kvale \& Brinkmann 2009). These interviews were chronologically structured on crucial moments of their school career: at the end of primary education (when deciding on a secondary 
school), at the end of Grade 8 (when deciding on the ability track for the subsequent years of secondary school), at the end of Grade 9 (when deciding on one of the four educational profiles), and at the end of Grade 12 (when deciding on the next step after completing secondary education). Students were asked to provide a narrative of their school careers using these crucial moments. The interviews were held at their homes or in a public place. They lasted between 15 and 40 minutes, were taped on video, and were transcribed into written protocols. Nine students were interviewed after they had completed secondary school. One student was interviewed at the end of his final year of secondary school.

\section{Analyses}

The national test scores are split into percentile scores for Dutch language and Mathematics. Crosstabs and chi-squared statistics were used to analyze the student test scores. Students who were officially registered as students having dyslexia and/or dyscalculia were left out of the analyses. Furthermore, matrix analysis was used to analyze the narratives from the life-world interviews (cf. Miles \& Huberman 1994). A cross-case matrix was setup within the column for the 10 cases, grouped into two groups (with low numeracy and high literacy, or high numeracy and low literacy) and in the rows the moments of decision and background information of the students, such as their test scores and marks and their continuing school career. With this matrix both horizontal analyses (a particular moment of decision between all cases) and vertical analyses (a case description for all moments of decision) were performed. The matrix was checked for consistency and completeness by a second researcher, who was not involved in this study.

\section{Results}

\subsection{Students with High Proficiency in either Mathematics or Language}

Data from the national test at the end of primary education were available for 598 students. In Table 1, we summarize the scores of these students on the Dutch language and Mathematics in terms of percentiles. The upper-right corner of Table 1, shows the number of students who scored $51 \%$ or higher on Mathematics and $50 \%$ or lower on Dutch language. The lower-left corner of Table 1, shows the number of students who scored $51 \%$ or higher on Dutch language and $50 \%$ or lower on Mathematics.

From Table 1 we see that the number of students with high proficiency in Mathematics and low proficiency in language (26 students) is smaller than the number of students with a reversed profile (66 students).

Table 1. Number of Students for Each Percentile for the Parts Dutch Language and Mathematics of the National Test at the End of Primary Education

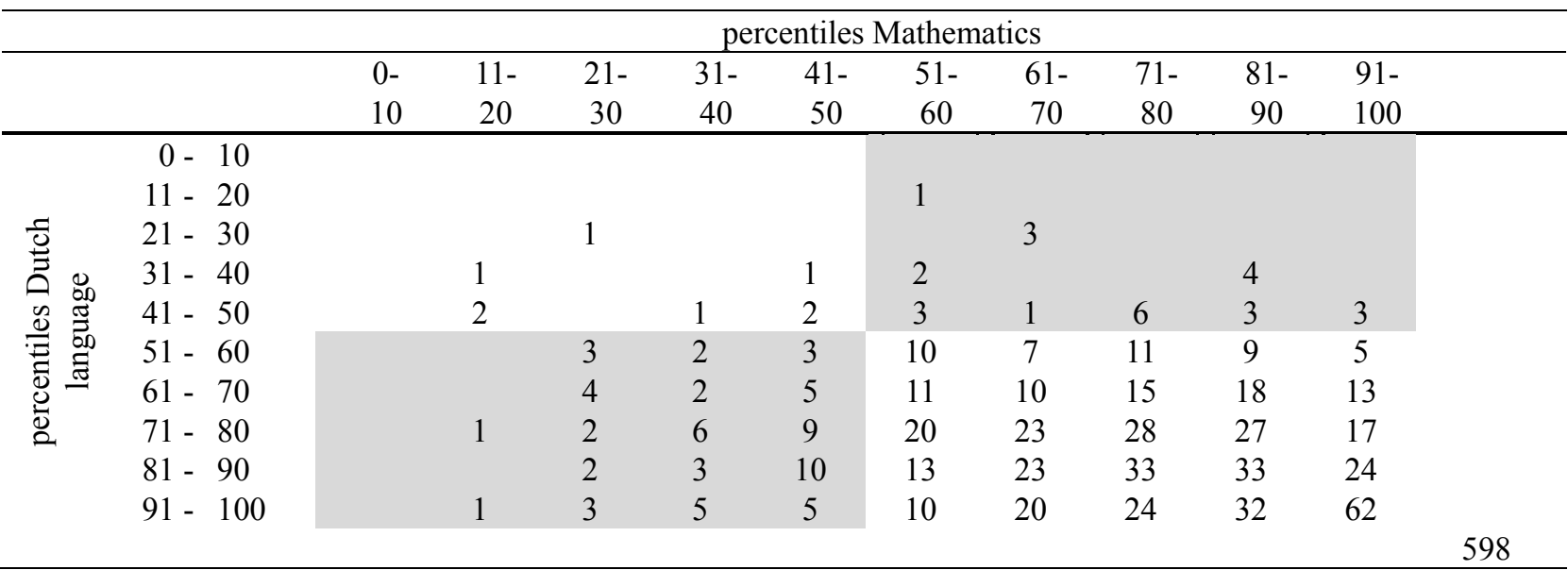

In Table 2, we present the number of students who reached Grade 9 of pre-university education within the regular time frame of two years. Of the 598 students starting in Grade 7, 328 reached Grade 9 in pre-university education in two years. A chi-squared test showed a significant relationship between the number of students successfully reaching Grade 9 and the grouping on the basis of the test scores at the end of primary education $\left(\chi^{2}(3, N=598)=4.4 ; p\right.$ $<.001$ ) with $25 \%$ successful students in the low-achievement group, $38 \%$ in the one-sided language proficiency 
group, $15 \%$ in the one-sided Mathematics proficiency group and $60 \%$ in the high-achievement group. The difference between numbers of students in both one-sided proficiency groups (language vs. Mathematics) was significant as well $\left(\chi^{2}(1, \mathrm{~N}=92)=4.4 ; \mathrm{p}=.004\right)$. This difference may be explained by the fact that students fail or pass in Grade 8 on the basis of four language subjects and only two subjects related to numeracy (Mathematics and Physics). Moreover, because realistic mathematics education is used in this school (as in many other secondary schools in the Netherlands), Mathematics and Physics require language skills as well (Gravemeijer \& Doorman, 1999).

Table 2. Number of Pre-University Students Passing to Grade 9 in Pre-University without Delay, Clustered in Groups Based on The Percentile Scores at the End of Primary Education (see Table 1)

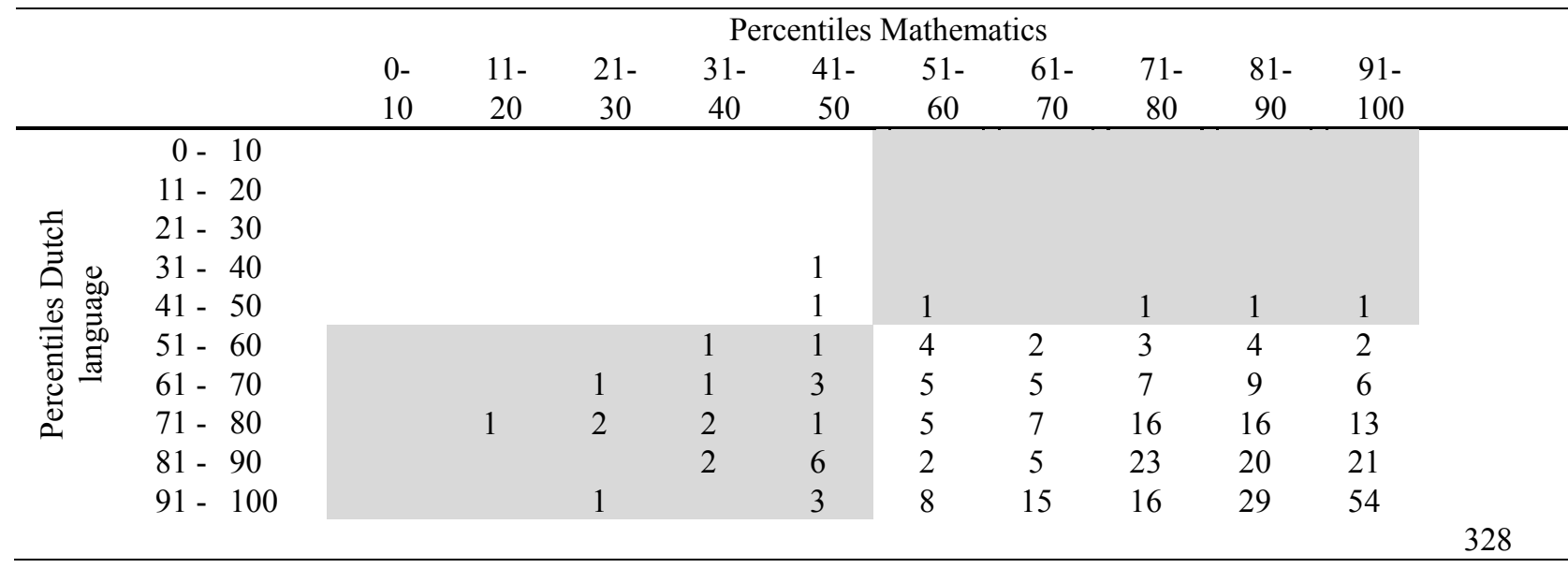

\subsection{Students' Perceptions of Their School Career}

In Table 3, background profiles are summarized of the ten students who were interviewed. All students started secondary school in combination classes of pre-university and senior general secondary education. All the participants continued after Grade 8 to the lower track (senior general secondary education) and then continued their school career in higher vocational education (except for Joe who was still in secondary school at the time of the interview). The five students (all girls) from the one-sided language proficiency group chose a social profile in Grade 10 (Culture \& Society or Economics and Society) and all the students from the one-sided Mathematics proficiency group choose a technological profile, except the only girl in this group who chose a social profile.

\subsection{Primary Education}

In primary school, most students were already aware of their one-sided proficiency in either Dutch language or Mathematics. Although all students were high-achievers in general, two students of one-sided language proficiency group reported receiving additional support to develop their numeracy. But they also reported positive school experiences based on their literacy. For example, one student loved to write short stories in primary school. For students from the one-sided Mathematics proficiency group the situation in primary education was the other way around. Below is a quote from the interview with a student of the one-sided language proficiency group.

Yes, by the time calculation was a real thing in primary education, I had already gotten behind. I always had some trouble with numbers and calculating. Then I really got behind. Sometimes a teacher spotted this and tried to do something about it. One teacher tried to help me. But actually I was never tested, you know, I never had a test to diagnose whether I had trouble with numbers and calculating. I noticed though, that I was good in grammar and language. I loved to read. I even participated in a reading competition, which I won. (Interview with Amber)

\subsection{National Test at the End of Primary Education}

The test score did not have different consequences for the 10 students. All students were selected for a combination of the two highest tracks in secondary education: Senior general secondary education and Pre-university education. The five students from the one-sided language proficiency (all girls) showed a large difference in their percentile scores on Dutch language (between 74 and 95\%) and Mathematics (between 15 and 58\%). This difference was somewhat smaller for the one-sided mathematics proficiency group (four boys and one girl) with scores between 45 and 58\% for Dutch language and between 70 and $93 \%$ for Mathematics. 
Table 3. Participants in the Interviews

\begin{tabular}{|c|c|c|c|c|c|c|c|c|c|c|c|}
\hline & \multirow[b]{2}{*}{ Age } & \multicolumn{2}{|c|}{$\begin{array}{c}\text { Percentile test score } \\
\text { half Grade } 6\end{array}$} & \multicolumn{6}{|c|}{ Marks end of Grade $8^{2}$} & \multirow[b]{2}{*}{$\begin{array}{c}\text { Profile } \\
\text { Grade } 10^{5}\end{array}$} & \multirow[b]{2}{*}{$\begin{array}{l}\text { After secondary } \\
\text { education }\end{array}$} \\
\hline & & $\begin{array}{c}\text { Dutch } \\
\text { language }\end{array}$ & Mathematics & $\mathrm{Du}$, & Fr, & $\mathrm{Ge}, \mathrm{E}$ & & $\mathrm{Ma}$ & $\mathrm{Ph}^{4}$ & & \\
\hline \multicolumn{12}{|c|}{ One-sided language proficiency students ${ }^{1}$} \\
\hline Amber & 17 & 95 & 37 & 7 & 7 & 7 & 8 & 5 & 5 & $\mathrm{CS}$ & $\mathrm{HVE}^{6}$ legal studies \\
\hline Barbara & 23 & 95 & 58 & 6 & 7 & 7 & 9 & 5 & 4 & $\mathrm{CS}$ & $\begin{array}{l}\text { HVE English } \\
\text { language }\end{array}$ \\
\hline Christine & 18 & 74 & 36 & 7 & 6 & 7 & 9 & 5 & 6 & $\mathrm{CS}$ & $\begin{array}{l}\text { HVE social work } \\
\text { and teacher } \\
\text { education }\end{array}$ \\
\hline Diana & 17 & 93 & 15 & 7 & 6 & 7 & 9 & 4 & 6 & $\mathrm{CS}$ & HVE social work \\
\hline Eliza & 18 & 87 & 24 & 7 & 7 & 8 & 6 & 5 & 6 & ES & $\begin{array}{l}\text { HVE legal studies } \\
\text { and commerce }\end{array}$ \\
\hline \multicolumn{12}{|c|}{ One-sided mathematics proficiency students } \\
\hline Fred & 20 & 48 & 70 & 6 & 5 & 6 & 7 & 7 & 8 & NT & $\begin{array}{l}\text { HVE mechanical } \\
\text { engineering }\end{array}$ \\
\hline Greg & 17 & 58 & 89 & 6 & 3 & 6 & 6 & 7 & 7 & NT & $\begin{array}{l}\text { HVE water } \\
\text { engineering }\end{array}$ \\
\hline Howard & 18 & 56 & 93 & 6 & 6 & 6 & 6 & 7 & 7 & NT & $\begin{array}{l}\text { HVE applied } \\
\text { Physics }\end{array}$ \\
\hline Isabel & 24 & 56 & 86 & 6 & 6 & 8 & 7 & 7 & 7 & ES & $\begin{array}{l}\text { HVE teacher } \\
\text { education }\end{array}$ \\
\hline Joe & 17 & 45 & 92 & 5 & 6 & 6 & 5 & 9 & 7 & NT & $\begin{array}{l}\text { Grade } 11 \text { senior } \\
\text { general secondary } \\
\text { education }\end{array}$ \\
\hline
\end{tabular}

\subsection{The First Two Years of Secondary Education (Grade 7 and 8)}

The school career of the students during the two first years of secondary education was somewhat bumpy. While these students were used to attending classes with one fixed combination of students and one teacher, in secondary school they attended a different class for each subject and were taught by different teachers. As expected, the picture we had from the final school year in primary education continued into the first two years of secondary education. Students from the one-sided language proficiency group performed well in all language subjects and had difficulties with Mathematics, with a reversed picture for the other five students. Below a student of the one-sided language proficiency group describes her struggle with Mathematics and Physics as well as her preference for language subjects.

Generally, I had good marks in the first two years of secondary education. But I also had some difficulties. On the first Math exam I received a C, but after that I only got Ds, Es and Fs. I think I only received a $\mathrm{C}$ twice in three years; the other marks were lower. Yet for the other subjects $\mathrm{I}$ received higher marks. For the Dutch language, I received high marks just as I did in the other languages. For French as a foreign language I received really high marks. Memorizing words, that kind of things, memorizing sentences, that was quite easy for me. And in Physics, I managed to memorize the written information, but then, if we worked with formulas it really went wrong. Yes, I really did not understand Physics. Just as in Mathematics, using formulas, I never understood them. The Math teacher could repeat his explanation of the formulas ten times. I just did not get it. He wanted me to ask as many questions as I wanted, but I just could not manage to formulate questions. (Interview with Christine)

Just the opposite experiences were reported by the students of the one-sided mathematics proficiency group. Below, one of these students describes his struggle with languages and his positive motivation for Mathematics. 
Mathematics, Music and Technology, I loved these. These subjects all went well and I received high marks in these subjects. But English language, yes, that was the subject that went badly. I really was not interested in it. Mathematics was the subject I was interested in. I love to work with numbers, to calculate. Learning languages was not my thing. French language required me to memorize all these words. I am more interested in completing assignments and learning from it, than in memorizing, or learning by heart. I have troubles with that, I don't like it. And English language, yes, you have to put in a lot of energy, to memorize the words, to learn things by heart. (Interview with Joe)

\subsection{At the End of Grade 8}

It came as no surprise to all these students, because of their weak performance in a part of the curriculum, that they could not continue their school career at the level of pre-university education. They already expected that they had to begin in Grade 9 in the lower ability track, in senior general secondary education.

\subsection{Third Year of Secondary Education (Grade 9)}

All ten students moved into Grade 9 in senior general secondary education. Yet they experienced the same problems as they had in the first two years of secondary education. Students from the one-sided language proficiency group had difficulties with Mathematics and students from the one-sided mathematics proficiency group performed poorly in the language subjects. Attending the lower ability track did not solve the problems students had experienced with either Mathematics or the language subjects. Moreover, these students reported that they out-performed their peers in the subjects they already performed well in during the first two years. Below a student of the one-sided language proficiency group reports on her ability level in both Mathematics and in language subjects.

For me, it was clear that I should stay at the level of senior general secondary education. Probably, I could have managed to complete pre-university education, but at that time I had difficulty with Mathematics. I thought Math would be much more difficult in pre-university education. In the other subjects, I had no problems. I remember things easily, which is of course convenient with languages, but irrelevant for Mathematics. In Math, you have to use your knowledge. You must be able to calculate. For the languages and subjects other than Math and Economics, senior general secondary education was not really challenging. Even when I did not put a lot of energy into these subjects, I passed the exams. The exceptions were Math and Economics. These were still too hard for me, even at the lower level of senior general secondary education. (Interview with Eliza)

\subsection{Choosing a Study Profile at the End of Grade 9}

At the end of Grade 9 of senior general secondary education, students have to choose a particular study profile, which shapes their curriculum in the final two years. Although for most Dutch students the process of deciding on their profile is a complicated one, for these students it was quite easy. Because they performed well in either Mathematics or language, they chose the educational profiles in which either Mathematics or the language subjects were the major component. Students from the one-sided language proficiency group chose Culture \& Society (4 students) or Economy \& Society (1 student). Students from the one-sided mathematics proficiency group chose the profile Nature \& Technology (4 students). The only exception in this latter group was the only girl who chose a profile of Economy \& Society. Students' motivation for their decisions was similar. They performed well in the subjects that were part of the particular profile, and performed poorly in subjects that were part of the profiles they did not choose. They did not even consider other choices. Below, a student of the one-sided mathematics proficiency group describes how he considered his choice of a certain profile.

I chose the Nature \& Technology profile. The languages were not my preference. Dutch language and French language, I didn't like them. There was no commitment. And then I got low marks. Mathematics, Physics and Chemistry, I liked these. In the first year we got Technology and Visual arts. I thought that was great. My profile choice was very clear to me, yes, Nature \& Technology. Other profiles I did not even think about. Technology, that's it! (Interview with Greg)

\subsection{The last Two Years of Secondary Education (Grade 10 and 11)}

In all four educational profiles, Dutch and English are compulsory. Although these subjects were still the most difficult ones for students in the one-sided mathematics proficiency group, all students succeeded in finishing secondary education in the remaining two years. Remarkably, students from both groups who chose Economics in their profiles reported difficulties with this subject. Economics asks for both literacy and numeracy skills, depending on which aspects of economics are covered. 
I can remember that in Grade 9 I still followed Math but I had more and more difficulties. I just thought; I cannot manage it anymore. Until that time I had Cs or Ds, but they became Fs. I also thought about tuition, but I just thought, in grade 10 I will not take Math classes anymore. I chose Management and Organization [with a major component Business administration], as a kind of compromise, because my parents wanted me to take a school subject with numbers. This subject merges more or less Math and Economics. In the beginning, I had difficulties once more with numbers and calculating. But after a while, I managed to get Cs. At the end of Grade 11, it was still not the best mark I had, but I tried my best. (Interview with Diana)

\subsection{Orientation to Continuing Education and Professional Career}

Similar to their process of deciding a study profile two years earlier, students again focused on their strengths (and tried to escape their weaknesses) in orientating themselves for the next step after secondary education. The students were aware that certain steps were not recommended or not even possible for them. The students from the one-sided language proficiency group decided to continue their education with studies in higher education that did not require Mathematics for enrollment. The other students decided to attend technology studies in higher education, which matched their study profiles in secondary education. The only girl in that group, who chose a profile of Economy \& Society, continued with teacher training in primary education.

Below, the interview with Diana, linked the choice of her profile, Culture \& Society, to her future job:

Well I chose Culture \& Society, a more language-oriented profile. I even chose an additional language, I really liked that. And then there were the subjects of Visual arts and design, the more creative subjects. But in all cases, no Mathematics. No Mathematics! I had had so many difficulties during the first three years. I just thought I cannot cope with this for two more years. My parents advised me to choose Mathematics in order to broaden my prospects in continuing education and future jobs. But I just said: no, if a job asks for Mathematics know-how, I do not even want to take it. (Interview with Diana)

\subsection{Continuing Education and Professional Career}

Isabel, from the one-sided mathematics proficiency group, who continued in higher education with teacher training, already worked in primary education at the time of the interview. She reported that she had many difficulties with the language tests that were administered in teacher training. She also reported that she was a bit anxious when giving instruction on language matters, but showed confidence in her Mathematics teaching. One student was about to start with continuing education and three students were in their first year of continuing education. One of the girls in the one-sided language proficiency group changed to teacher training for primary education and reports that she experienced difficulties with teaching Mathematics. The other five students switched to another higher education program because of a lack of interest in the subject. Below an interview with Amber, confirmed that the lack of numeracy skills dominated her choice for continuing education:

This [difficulties with Mathematics] certainly influenced my choice. Of course in continuing education so many programs are not possible [without Mathematics]. But numbers and calculating, I just tried to avoid these. This didn't have a massive influence on the choices I made, but it certainly had some influence on my further career. (Interview with Amber)

One student of the one-sided Mathematics proficiency group said that, in the first year of the technical college, he had great difficulty with English textbooks and lectures in English. After much practice and training it is going well for him now.

\subsection{Implications for Everyday Life}

Most respondents look back with good feelings about their secondary school years. The students feel no resentment that, despite their good performance in parts of the curriculum, they could not continue the pre-university stream. They found it quite normal that they had to continue their educational career at a lower level, because their performance in some school subjects was not good enough. In the following years they chose for their strengths and learned to circumvent their weaknesses. In some situations in daily life, they were again confronted with their one-sided proficiency when they found that even the most basic skills were not present. Two students from the one-sided language proficiency group told us that they, in their summer job in a shop, had problems with making correct change.

I work in a bakery. I must make change for the customer. If they gave me a tenner, ..., I spent a long time 
calculating the change. In the beginning I became stressed. They [the customers] had to wait and I was counting. After much practice, I succeeded. (Interview with Diana)

\section{Discussion and Conclusion}

For most students in Dutch secondary education the system is appropriate. When students' achievements are at least sufficient in all school subjects, they are able to pass the selection in the first years of secondary education and continue their school career in a track that meets their ability level. Students who perform below sufficient in some school subjects follow a track that fits with their lowest performance, no matter how good they perform in other parts of the curriculum. This means that the Dutch educational system supports intermediate performance in a full range of school subjects, whereas students with one-sided proficiency seem not to be able to fully exploit their talents.

Although we interviewed only 10 students, their stories clearly show a common experience in their school careers. They were not allowed to continue pre-university education, because they performed low in either language or mathematics. In the years after they continued at a lower track (senior general secondary education), none of them had reached the university level at the time of this survey. This is despite the possibility offered by the Dutch system to go to the pre-university track after succeeding in the senior general education (see Figure 1). The disadvantages inherent in this detour are the public costs and the extra years needed to reach university level. It also asks much perseverance from the students. Another complication is that mathematics and a second foreign language are compulsory school subjects at pre-university education. Some students did not follow these subjects in the last years of senior general education. This means that they will start with a disadvantage at the pre-university track. Following the lower ability track was not a solution for the problems these students faced. They still experienced difficulty with the school subjects in the weaker domain and a lack of being challenged in the school subjects of their stronger domain. In higher education or their profession, they still report difficulties with subjects that are related to the subjects in which they performed poorly in school. Following a curriculum at the level of their weakest school subject did not seem to enhance their skills and knowledge in that domain. Rather it prevented them from further increasing their skills and knowledge in the domain of their proficiency. Although the students of the current study did not report extreme feelings of frustration, their experiences are in line with feelings of students who perform well in Mathematics and poor in reading reported in other studies (Lange \& Meaney, 2011).

Experimenting with teaching at different levels for different school subjects could be a way to align learning and instruction with the ability levels of students. This would give students with, for example, a one-sided mathematic proficiency the opportunity to perform in the mathematical subjects at pre-university level and in the languages at senior general level. Another solution would be to abandon the requirement for a second foreign language in the pre-university track, thus allowing one-sided mathematics proficiency students to fully focus on English as a foreign language. On the other hand, the one-side language proficiency students would get the opportunity to perform in languages at a pre-university level and in mathematics at a lower level, sufficiently supporting skills needed for social studies and daily life.

However, these kinds of experiments should be monitored and evaluated. Differentiating the level students can follow within the regular Dutch educational system should challenge all students to perform at their highest level without having any negative consequences for the school subjects in which students might be less talented. Providing education at a personalized ability level is one of the major challenges of the egalitarian Dutch educational system. Accompanying research is necessary to evaluate the balance between the costs and benefits of such a system.

\section{References}

Adelman, C. (1999). Answers in the tool box: Academic intensity, attendance patterns, and bachelor's degree attainment. Washington, DC: U.S. Department of Education.

Argys, L. M., Rees, D. I., \& Brewer, D. J. (1996). Detracking America's schools: Equity at zero cost? Journal of Policy Analysis and Management, 15(4), 623-645. http://dx.doi.org/10.1002/(SICI)1520-6688(199623)

Becker, M., Lüdtke, O., Trautwein, U., Köller, O., \& Baumert, J. (2012). The differential effects of school tracking on psychometric intelligence: Do academic-track schools make students smarter? Journal of Educational Psychology, 104, 682-699. http://dx.doi.org/10.1037/a0027608

Bernhardt, P. E. (2012). Making decisions about academic trajectories: a qualitative study of social studies teachers' course recommendation practices. Dissertation. George Washington University, Washington. 
Betts, J. R., \& Shkolnik, J. L. (2000). The effects of ability grouping on student achievement and resource allocation in secondary schools, Economics of Education Review, 19(1), 1-15. http://dx.doi.org/10.1016/S0272-7757(98)00044-2

Brunello, G., \& Checchi, D. (2007). Does school tracking affect equality of opportunity? New international evidence. Economic Policy, 22, 781-861. http://dx.doi.org/10.1111/j.1468-0327.2007.00189.x

Cobb-Clark, D., Sinning, M., \& Stillman, S. (2012). Migrant youths' educational achievement: The role of institutions. The ANNALS of the American Academy of Political and Social Science, 643, 18-45. http://dx.doi.org/10.1177/0002716212440786

Choy, S. P., Horn, L. J., Nunez, A-M., \& Chen, X. (2000). Transition to college: what helps at-risk students and students whose parents did not attend college. New directions for Institutional Research, 107, 45-63. http://dx.doi.org/10.1002/ir.10704

Darling-Hammond, L., \& Post, L. (2000). Inequality in teaching and schooling: Supporting high-quality teaching and leadership in low-income schools. In R.D. Kahlenberg (Ed.), A notion at risk: Preserving public education as an engine of social mobility (pp. 127-167). New York; The Century Foundation Press.

Dobbelsteen, S., Levin J., \& Oosterbeek H. (2002). The causal effect of class size on scholastic achievement: distinguishing the pure class size effect from the effect of changes in class composition. Oxford Bulletin of Economics and Statistics, 64, 17-38. http://dx.doi.org/10.1111/1468-0084.00003.

Duflo, E., Dupas, P., \& Kremer, M. (2011). Peer effects, teacher incentices, and the impact of tracking: Evidence from a randomized evaluation in Kenya. American Economic Review, 101, 1739-1774. http://dx.doi.org/10.1257/aer.101.5.1739

Figlio, D. N., \& Page, M. E. (2002). School choice and the distributional effects of ability tracking: does separation increase inequality? Journal of Urban Economics, 51, 497-514. http://dx.doi.org/10.1006/juec.2001.2255

Gravemeijer, K., \& Doorman, M. (1999). Context problems in realistic mathematics education: a calculus course as an example. Educational Studies in Mathematics, 39, 111-129. http://dx.doi.org/10.1023/A:1003749919816

Hanushek, E. A., \& Wösmann, L. (2006). Does educational tracking affect performance and inequality? Differences-in-differences evidence across countries. The Economic Journal, 116, C63-C76. http://dx.doi.org/10.1111/j.1468-0297.2006.01076.x

Kalogrides, D., \& Loeb, S. (2013). Different teachers, different peers: The magnitude of student sorting within schools. Educational Researcher, 42, 304-316. http://dx.doi.org/10.3102/0013189X13495087

Kelly, S. (2008). Social class and tracking within schools. In L. Weis (Ed.), The way class works. Readings on school, family and the economy (pp. 210-224). New York, NY: Routledge.

King, J. (1996). The decision to go to college: Attitudes and experiences associated with college attendance among low-income students. New York: The College Board.

Kulik, C., \& Kulik, J. (1982). Effects of ability grouping on secondary school students: a meta-analysis of evaluation findings. American Educational Research Journal, 19, 415-428. http://dx.doi.org/10.3102/00028312019003415

Kvale, S., \& Brinkmann, S. (2009). InterViews: Learning the craft of qualitative research interviewing ( $2^{\text {nd }}$ ed.). Los Angeles: Sage.

Lange, T., \& Meaney, T. (2011). I actually started to scream: emotional and mathematical trauma from doing school mathematics homework. Educational Studies in Mathematics, 77, 35-51. http://dx.doi.org/10.1007/s10649-011-9298-1

Lucas, S. R. (2001). Effectively maintained inequality: education transitions, track mobility, and social background effects. American Journal of Sociology, 106, 1642-1690. http://dx.doi.org/10.1086/321300

Miles, M. B., \& Huberman, A. B. (1984). Qualitative data analysis: A source book of new methods. Beverly Hills, CA: Sage.

Oakes, J. (1992). Can tracking research inform practice? Educational Researcher, 21(4), 12-21. http://dx.doi.org/10.3102/0013189X021004012

Onderwijsraad. (2010). Vroeg of laat. Onderwijsraad, Den Haag. The Netherlands.

Österholm, M. (2006). Characterizing reading comprehension of mathematical texts. Educational Studies in 
Mathematics, 63, 325-346. http://dx.doi.org/10.1007/s10649-005-9016-y

Ríordáin, M. N., \& O’Donoghue, J. (2009). The relationship between performance on mathematical word problems and language proficiency for students learning through the medium of Irish. Educational Studies in Mathematics, 71, 43-64. http://dx.doi.org/10.1007/s10649-008-9158-9

Sund, K. (2013). Detracking Swedish compulsory schools: Any losers, any winners? Empirical Economics, 44, 899-920. http://dx.doi.org/10.1007/s00181-011-0532-6

Van der Werfhorst, H., \& Mijs, J. (2007). Onderwijsdifferentiatie en ongelijkheid. Nederland in vergelijkend perspectief. Amsterdam: Universiteit van Amsterdam.

Zepp, R. A. (1981). Relationships between mathematics achievement and various English language proficiencies. Educational Studies in Mathematics, 12, 59-70. http://dx.doi.org/10.1007/BF00386046 